Vol. 14, n² | 2010

Varia

\title{
Fijnaut (Cyrille), A history of the Dutch police
}

Amsterdam, Boom Publishers, 2009, 203 pp. , ISBN 9789085064565

Jonas Campion

\section{OpenEdition}

Journals

Édition électronique

URL : https://journals.openedition.org/chs/1216

DOI : $10.4000 /$ chs. 1216

ISSN : 1663-4837

Éditeur

Librairie Droz

\section{Édition imprimée}

Date de publication : 1 décembre 2010

Pagination : 149-151

ISBN : 978-2-600-01470-0

ISSN : 1422-0857

\section{Référence électronique}

Jonas Campion, « Fijnaut (Cyrille), A history of the Dutch police », Crime, Histoire \& Sociétés / Crime,

History \& Societies [En ligne], Vol. 14, $n^{\circ} 2 \mid 2010$, mis en ligne le 02 décembre 2010, consulté le 23 mars 2022. URL : http://journals.openedition.org/chs/1216; DOI : https://doi.org/10.4000/chs.1216 
Fijnaut (Cyrille), A history of the Dutch police, Amsterdam, Boom Publishers, 2009, 203 pp., ISBN 9789085064565

Ces dernières années, Cyrille Fijnaut a coordonné un projet de recherches portant sur l'histoire sociopolitique de l'appareil policier des Pays-Bas aux XIX ${ }^{\mathrm{e}}$ et XX siècles. En 2007, à l'issue de ce projet collectif de grande ampleur, trois tomes, traitant respectivement des polices locales (Guus Meershoek), des polices nationales (Jos Smeets), des associations et de la formation professionnelle (Ronald van der Wal) étaient publiés en néerlandais. Cyrille Fijnaut proposait, dans un quatrième volume, une vision globale de l'évolution de l'appareil policier dans le «tourbillon de l'histoire $»^{10}$.

Afin de rendre ces travaux accessibles au plus grand nombre, est aujourd'hui publié en anglais par ce dernier auteur, un résumé des principaux résultats jusqu'ici obtenus. Dit autrement, A history of the Dutch police ne doit pas être lu de manière indépendante des quatre principales publications issues du projet initial.

Car, l'essentiel des regrets qui apparaissent à sa lecture, notamment le caractère parfois trop succinct des développements proposés, ou la faible bibliographie proposée, ne résiste pas à l'analyse générale de cette série. À cet égard, nous ne pouvons que conseiller le recours aux données archivistiques et bibliographiques présentes dans les quatre publications initiales. Elles permettent au chercheur de disposer d'un panorama presque exhaustif de la matière disponible pour construire une histoire policière des Pays-Bas. Lesquels matériaux éclairent aussi l'histoire européenne, du fait de la conquête française des territoires néerlandais (1795); de l'instauration, après le congrès de Vienne, d'un royaume des Pays-Bas comprenant l'actuelle Belgique, ou des contacts policiers entre l'Allemagne et les Pays-Bas dans l'entredeux-guerres.

Illustrée, la synthèse de Cyrille Fijnaut propose en six chapitres, une progression chronologique, depuis l'occupation française du pays jusqu' aux dernières réformes menées en 2006. Dans ce lent processus de maturation de l'appareil policier, la Seconde Guerre mondiale constitue un moment d'accélération marquant, aux conséquences majeures en termes d'organisation policière. Car, bien que les autorités politiques néerlandaises s'en défendent, la majorité des réformes imposées durant l'Occupation du pays, puisqu'elles s'inscrivent pour partie dans le prolongement de débats anciens, sont confirmées après la guerre. Premier aboutissement marquant après plus d'un siècle d'hésitations et de débats, l'Occupation constitue le point de départ des réflexions et réformes menées aux Pays-Bas tout au long du second vingtième siècle. C'est pourquoi la guerre constitue, avec ses suites, le cœur des propos de Cyrille Fijnaut (chapitres 4 et 5).

Le parcours proposé par ce spécialiste des questions policières contemporaines s'intègre résolument dans une réflexion actuelle sur l'organisation policière. Selon Fijnaut, ancrée dans un processus en devenir, la police néerlandaise est encore

10 Cyrille Fijnaut, De geschiedenis van de Nederlandse Politie. Een staatinstelling in de maalstroom van de geschiedenis, Amsterdam, Boom, 2007, 1029 p.; Guus Meershoek, De geschiedenis van de Nederlandse Politie. De Gemeentepolitie in een veranderende samenleving, Amsterdam, Boom, 2007, 546 p.; Jos Smeets, De Geschiedenis van de Nederlandse Politie. Verdeelheid en eenheid in het rijkspolitieapparaat, Amsterdam, Boom, 2007, 616 p.; Ronald van der Wal, De geschiedenis van de Nederlandse Politie. De vakorganisatie en het beroepsonderwijs, Amsterdam, Boom, 2007, $619 \mathrm{p}$. 
appelée à évoluer vers une unification accrue, pour répondre aux enjeux de sécurité, d'ordre ou d'exercice de la justice des sociétés contemporaines (p. 192). C'est la lente et difficile évolution d'un complexe policier à l'origine morcelée entre cinq institutions, vers la centralisation et la rationalisation, qui sous-tend les analyses de l'auteur.

Avec nuances, l'essentiel du propos décrit les rythmes, causes et difficultés de l'adaptation institutionnelle des polices néerlandaises face aux mutations de la société. Il ne s'étend qu'accessoirement et de manière générale sur les pratiques policières quotidiennes, pour se concentrer presqu'exclusivement sur une lecture institutionnelle, idéologique et politique de l'histoire policière. À cet égard, comme Cyrille Fijnaut l'avait déjà mis en lumière ${ }^{11}$, ce sont les moments de tensions, de crises ou de scandales qui attirent l'attention, en tant qu'accélérateurs de réformes. Ils entraînent la succession des actes législatifs qui veulent apporter une réponse définitive à la question policière, mais qui s'avèrent rapidement insatisfaisants (comme en 1851, 1935, 1945, 1957, 1993...). Face à cette multiplication des tensions, la recherche d'un compromis quant à la structure à donner à l'organisation policière est omniprésente. Par exemple, tout au long des $\mathrm{XIX}^{\mathrm{e}}$ et $\mathrm{XX}^{\mathrm{e}}$ siècles, les débats sont permanents quant au degré de centralisation nécessaire, ou quant à la nécessité de disposer de force(s) militaire(s) et nationale(s) de police. La lente expansion de la Koninklijke Marechaussee témoigne de la prégnance de ces oppositions. D'autres questions, comme le rôle judiciaire de la police, structurent également les réflexions et débats qui traversent alors l'espace public.

L'intérêt de la recherche est de prendre en compte la diversité des points de vue qui interviennent dans le débat public (partisans, populaires et professionnels), et de souligner l'importance des traditions politiques (notamment locales ou confessionnelles) pour leur compréhension. Car, et c'est là une spécificité néerlandaise, le pays est traversé par un clivage religieux entre catholiques et réformés. Ce dernier se retrouve également au sein des organisations corporatives et professionnelles. Or, celles-ci sont des acteurs de premier ordre de la question policière: elles insistent sans relâche sur la nécessaire professionnalisation des policiers, ou sur l'amélioration de leurs conditions de vie, deux domaines qui donnent également lieu à des crispations récurrentes depuis le $\mathrm{XIX}^{\mathrm{e}}$ siècle.

Cette approche sociopolitique possède, on l'aura compris, de nombreux atouts, au premier rang desquels la diversité des perspectives abordées. Elles permettent de faire de l'institution policière un objet d'histoire, au cœur des relations sociales et politiques. À côté des débats identitaires sur le rôle et l'organisation policière, l'influence des enjeux sociaux, économiques et politiques en tant qu'événements auxquels doit s'adapter la police, est clairement souligné. À cet égard, si la synthèse de Fijnaut est évidemment éclairante sur les spécificités néerlandaises et les grands tournants de l'histoire de ce pays (comme l'affaire Oss ou les émeutes de Jordaan pour l'entre-deux-guerres), elle est également pertinente pour une lecture à l'échelle européenne de l'évolution des modèles et des fonctions policières. Dans cette logique, elle met en lumière les invariants transnationaux propres à la définition d'un appareil étatique de coercition. Les apports de l'argumentaire sont d'autant plus grands que la situation policière néerlandaise se définit comme un carrefour, au

11 Cyrille Fijnaut, Opdat de macht en toevlucht zij? Een historische studie van het politieapparaat als een politieke instelling, Anvers-Arnhem, Kluwer, 1979. 
cœur de l'Europe, où se rencontrent diverses influences policières, qu'elles soient française ou allemande.

Pour ces raisons, nous ne pouvons que saluer la mise à disposition d'un large public, par cette traduction en anglais, des principaux résultats issus du projet coordonné par Cyrille Fijnaut.

Jonas Campion

Université catholique de Louvain Centre d'histoire du droit et de la justice Jonas.Campion@uclouvain.be 